\title{
Bécquer y la Marquesa del Sauce
}

RUBÉN BENÍTEZ

Universidad de Los Angeles, California

Los años que van entre 1859 y 1861 son todavía años «misteriosos» en la vida de Gustavo A. Bécquer ${ }^{1}$. Tanto Franz Schneider ${ }^{2}$ en 1914 como Rica Brown en 1963, por citar sólo dos estudios biográficos fundamentales, lamentan la falta de datos concretos para reconstruir ese importante período de la vida del poeta en que escribió gran parte de las Rimas y Leyendas, las Cartas literarias a una mujer y el artículo sobre La Soledad de Ferrán. Años tumultuosos, además, en la experiencia amorosa de Bécquer, tan ligada siempre a su concepción de la poesía. El vacío informativo suele compensarse con las veladas alusiones de los amigos, muy cautos generalmente en cuanto a su vida íntima se refiere. De los recuerdos de esos amigos surgen, sin embargo, los primeros indicios de su relación, en ese período, con Julia Espín, presunta inspiradora de las Rimas y las Cartas literarias en las que se evoca a una mujer de húmedas pupilas azules. Esa mujer llena los ensueños del

1 Rica Brown se refiere al misterio de la vida íntima de Bécquer durante esos años en su Bécquer, Barcelona, Aedos, 1963, pág. 103.

2 Gustavo Adolfo Bécquer. Leben and Schaffen unter besonderer Betonungs des Chronologischen Elementes, Berna-Leipzig, Druck von Rober Noske, 1914. En mi traducción del libro (en Ensayo de bibliografía razonada de Gustavo Adolfo Bécquer, Buenos Aires, Universidad de Buenos Aires, 1961) las referencias que importan ocupan las págs. 34-37. 
poeta desde 1859 hasta fines de 1860 , como lo comprueba modernamente Rafael Montesinos ${ }^{3}$. El mismo Montesinos ha dado un cierre definitivo al episodio de los supuestos amores con Elisa Guillén, fraguados por Iglesias Figueroa, y ha desestimado por completo los poemas y escritos en prosa en que se alude al mismo episodio o se dan falsas pistas para su aceptación. No queda duda alguna sobre la relación con Julia Espín, cuyos alcances no conocemos y que se complica con la aparición de su hermana, objeto también de los galanteos del poe$\mathrm{ta}^{4}$. En diciembre de1860, Bécquer acude por primera vez al consultorio del médico Esteban Navarro, especialista en enfermedades venéreas, instalado en el pueblo de Noviercas, en Soria. Debió de conocer entonces a la joven de dieciocho años, Casta Esteban, hija del médico, en circunstancias no demasiado propicias para una nueva relación amoro$\mathrm{sa}^{5}$. En ese mismo mes, Gustavo A. Bécquer ingresa como redactor del diario El Contemporáneo, creado por el andaluz José Luis de Albareda. En abril de 1861 solicita la dispensa canónica en Madrid para casarse en Soria con Casta Esteban; el enlace se realiza el 19 de mayo. Julio Nombela afirma: «pensé, sin que el tiempo me haya hecho cambiar de opinión, que no casó sino que le casaron» ${ }^{6}$. Y siguiendo esa intuición, Dionisio Gamallo Fierros, que sitúa el viaje a Soria en marzo de 1861, afirma «que las circunstancias de la vida, y el anhelo de aturdirse, le fuerzan a contraer matrimonio con Casta Esteban» ${ }^{7}$. Entre el amor ideal por Julia Espín y el desastroso contrato matrimonial, y quizá superponiéndose a ambas experiencias, debió de existir un tercer amor, dolorosísimo para Bécquer, al que hacen referencias varios textos. El primero de ellos corresponde a Moreno Godino, quien dice al respecto:

Este poeta de la mujer sólo tuvo dos amores, pero amores como los suyos rinden toda una existencia. Como todo joven altamente organizado amó primero a una mujer de alta clase, o mejor dicho amó en ella el lujo que la ro-

3 En Bécquer, Biografía e imagen, Barcelona, Editorial R. M., 1977, págs. 21-39.

4 «Adiós a Elisa Guillén», en Insula, Madrid, 15-XII-1970.

5 Véase Heliodoro Carpintero, Bécquer de par en par, Madrid, Insula, 1957, y Rafael Montesinos, libro citado, págs. 51-58.

6 Impresiones y recuerdos, Madrid, La Ultima Moda, 1910-1913; los fragmentos que importan están recopilados por José María Monner Sans, Las Rimas y otras páginas, Buenos Aires, Estrada, 1947. La frase aparece en Montesinos, op. cit., pág. 51.

Páginas abandonadas del olvido en el ángulo oscuro. Madrid, Editorial Valera, 1948, pág. 26. 
deaba; pero no bastándole este marco esplendoroso, ni los atractivos de la línea aristocrática, quiso penetrar en el corazón de aquella mujer, predispuesta a la sensualidad pero que desconocía las idealidades de la pasión que Bécquer deseaba. Éste consumió todas sus energías juveniles en animarle en el quid divinum del amor y esta empresa imposible gastó su alma y su cuerpo» ${ }^{8}$.

Al comentar este explícito testimonio, Rica Brown se pregunta quién es esa enigmática mujer de alta clase quizá inspiradora de muchas otras Rimas ${ }^{9}$. Eusebio Blasco nos informa también de que Bécquer estuvo enamorado de una dama cuyo nombre silencia por tener ya «legal y legítimo dueño»: «Muy hermosa criatura, pero sin seso. Un admirable busto como el de la fábula, pero mujer tal vez incapaz de comprender las delicadezas del hombre que quiso vivir para ella» ${ }^{10}$. Gerardo Diego recoge, por su parte, de boca de parientes de Casta Esteban y de vecinos de Noviercas, la noticia de que antes de casarse con Casta, Bécquer había mantenido relaciones con una dama de rumbo de Valladolid, dama que era en realidad una marquesa ${ }^{11}$. Montesinos desecha de plano el testimonio de Moreno Godino, que nunca tuvo, al parecer, estrecha amistad con el poeta, aun cuando sólo se refiere a otro supuesto amor de Bécquer en Andalucía. Tampoco tiene Montesinos demasiada confianza, y con razón, en las palabras de Eusebio Blasco, un poco envidioso de la gloria de Bécquer. Pero para nada se detiene en comentar la afirmación de Gerardo Diego, muy creíble por derivar de un intelectual tan lúcido y tan conocedor de Soria y de sus alrededores. Aun cuando esas dudas tengan justificación, ¿cómo explicar la coincidencia de testimonios en nada relacionados entre sí? Sólo la existencia de un hecho real lo explica; como explica las aseveraciones de Rodríguez Correa y de otros con respecto al gusto con que Bécquer frecuentaba salones aristocráticos y se dejaba seducir por la belleza y por el lujo de la clase alta.

Creo en la existencia de esa dama de rumbo, esa marquesa. Y creo además haber hallado, en mi relectura de El Contemporáneo, cierta pista que merece ser investigada. En la Gacetilla de la Capital de los meses

8 «Semblanza de Gustavo Adolfo Bécquer» en Ilustración artística, Barcelona, XIV, 684 , págs. $115-116$.

9 Op. cit., pág. 121.

10 Mis contemporáneos. Semblanzas varias, Madrid, Francisco Álvarez, 1886, pág. 19. Aunque años después Blasco da el nombre de Julia Espín en otro lugar, nada autoriza a ligar esos textos. Ver Montesinos, op. cit., pág. 27.

11 «Los amores de Bécquer» en La Nación, Buenos Aires, 19 de julio de 1942. 
en cuestión, más precisamente entre enero y marzo de 1861, se relatan en forma apenas encubierta unos sucesos muy extraños en el contexto del periódico, que tienen como protagonistas al gacetillero y a una bellísima aristócrata. No se trata de una ficción sino de un relato de hechos reales, ya que esa aristócrata aparece con su propio nombre, la marquesa del Sauce, título de nobleza reconocido en España desde el siglo XVIII ${ }^{12}$.

La primera Gacetilla que ahora nos interesa apareció el 15 de enero de 1861:

Ayer vimos en la Fuente Castellana a la joven marquesa del Sauce. Esta mujer, notable por más de un concepto, ha venido a esta corte de incógnito, mas no hay velo que cubra a una hermosura tan radiante.

Incógnito que no es pues tal, al menos para el bien informado gacetillero que no tiene reparo en develarlo. El día 18 de enero se comenta un baile celebrado en casa de los señores de Prestos ${ }^{13}$ y se dice importunamente al final de la nota:

... Sin embargo, tuvimos el sentimiento de no ver allá a la joven y bellísima marquesa del Sauce, que según nuestras noticias debía asistir a dicho baile.

La misma marquesa del Sauce es protagonista de una bella estampa incorporada a la Gacetilla de la Capital el 19 de enero; estampa que tiene muchos puntos en común con La Caridad de Bécquer. En el Paseo de la Fuente Castellana, «a la hora en que el sol, compadecido de la desnudez de los árboles, enjugaba con tibios rayos de oro sus ateridas ramas», una joven sale a caminar por el parque, «dando motivo para que la húmeda arena, a guisa de una mujer charlatana, publicase a voces la imperceptible huella de su homeopático pie». Una anciana limosnera importuna a la paseante tirándole de la falda y exigiéndole caridad. La elegante dama la contempla con conmiseración y sus ojos se humedecen con lágrimas; pero, dice el redactor, «no encontramos

12 El marquesado del Sauce fue concedido por Real Despacho el 21 de mayo de 1744 al Vizconde don Manuel Escribano de la Fuente. Se trata de una familia castellana, oriunda de Añover del Tajo, Illescas (Toledo) pero extendida también a Aragón y Valencia. El Vizconde probó su nobleza en la Orden de Santiago en 1737. Su escudo de armas aparece jaquelado de oro y gules. Ver al respecto Julio de Atienza, Nobiliario español. Diccionario heráldico de apellidos españoles y de títulos nobiliarios, Madrid, Aguilar, 1948; pág. 1648.

13 Tengo dudas sobre este apellido, que reconstruyo de la copia borrosa del microfilm existente en la Biblioteca de la Universidad de California, en Los Angeles. 
después una gruesa perla en el sitio donde debió caer la lágrima del ángel de la caridad». La descripción de la dama y de sus actitudes sobrepasa los acostumbrados límites de la información periodística y tiene rasgos de deliberada cortesía y hasta de escarceo amoroso. «Lo que sí vimos fue salir de entre los pliegues del manto un brazo sobre el cual el sol, avaro de su belleza, lanzó sus más ardientes rayos»; en el brazo brilla un aderezo de pedrería que la dama entrega a la pordiosera. Uno de los jóvenes «leones» de Madrid devuelve la joya a su dueña y la remplaza por un fajo de billetes que deposita en la mano de la anciana. La nota termina con esta aclaración:

¿Quién era el ángel de la Fuente Castellana?, nos preguntarán en coro lectores y lectoras.

«¿Quién habría de ser, sino el duende mejicano que va siendo el incógnito más conocido de Madrid? ¿Quién habria de ser, hermosas mías (porque cuando ustedes preguntan se me da un ardite de todos los lectores); quien habría de ser, sino la bella marquesita del Sauce?

La marquesa tiene, pues, origen mejicano, y a ello se deben las menciones posteriores de su voz y de las modalidades características de su español. El día 20 se lee en el periódico la crónica de otro baile en Jovellanos, baile de máscaras celebrado el sábado anterior a esa fecha. El gacetillero se disculpa por su demora en escribir la crónica y declina toda responsabilidad porque de ese retardo tiene la culpa la «máscara blanca». Después de referirse a las dificultades que encuentra un cronista social, el autor habla de su encuentro con esa máscara blanca, «una mujer ángel o una máscara demonio, que tal la juzgamos al ver lo que de ella se decía y al oir lo que quiso decirnos, que no fue poco».

La máscara acusa al gacetillero de ser un adulador del bello sexo, refiriéndose a su constante actitud de galanteo. Se transcribe el diálogo entre los dos personajes; la joven aristocrática, protegida por la máscara, se permite, como ocurre habitualmente, una actitud de impudicia y de descaro. El autor describe la belleza insinuante de la dama, cuyo hermoso pelo negro cae sobre los hombros en ondulantes rizos y cuyos ojos de fuego brillan tras el antifaz, y la califica de «ser divino». La máscara blanca promete enviar al periodista su propio testimonio del baile, para que éste lo publique en lugar de sus exageradas crónicas; esa promesa origina la mencionada tardanza. El gacetillero jura publicar ese testimonio y lo hace invocando «sus ojos, que son los más negros, y sus dientes, que son los más blancos del mundo». Tras ello se despiden: «diónos un apretón con su aristocrática mano, nos iluminó con una sonrisa y desapareció». 
Pero la máscara blanca no envía la prometida gacetilla:

En castigo de su falta diremos: que todo el que vea a una máscara blanca, perfumada, ingeniosa, con ojos de fuego y boca de rosa, viva y nerviosa como una ardilla, tendrá delante a la embustera... es decir a la bella condesa [sic] del S..., recién llegada a Madrid en unión de su mágica belleza.

Su viaje tiene por objeto... pero será oportuno aplacemos esta indiscreción para otro día. Ha venido a la corte en busca de una esperanza... perdida en Andalucía: si la encuentra, hablaremos de ella; y la encontrará, porque la Providencia protege siempre a los que por amor padecen, creen y esperan.

Extrañas cosas para una crónica de bailes; aunque no sepamos cuál es la misión de ese viaje de incógnito es evidente que se trata de algo de carácter amoroso, una «esperanza» de amor originada en Andalucía; quizá en Cádiz, obligado puerto de mar para una viajera que proviene de México ${ }^{14}$.

En ese mismo número de El Contemporáneo Bécquer publica el artículo sobre La Soledad de Augusto Ferrán.

Los encuentros con la marquesa del Sauce se interrumpen. El poeta lamenta en la Gacetilla del día 22, la que los editores le atribuyen, la dureza de la realidad cuando sorprende a quienes, como él, persiguen sueños imposibles:

Finalmente, alguno que otro curioso, solo y pensativo, ve las miradas de todas aquellas personas, lee en ellas lo que significan, comprende cuanto encierran de irrealizable, se sonríe y cuando la sombra del crepúsculo dispersa a toda aquella sociedad, que pronuncia $H e$ aquí la noche, dice él, plagiando la frase, pero en el sentido de verdadero oráculo, He aquí la realidad: he aquí el desengaño» ${ }^{15}$.

El 26 de enero de 1861, el gacetillero recurre al verso, imitando los recursos del romance, para citar a la máscara blanca en el baile de esa noche:

\author{
Mascarita, mascarita \\ -la del blanco capuchón- \\ no me faltes esta noche \\ que te lo ruega mi amor. \\ Lleva la careta corta, \\ lleva grande el corazón \\ lleva en tus ojos de fuego \\ todos los rayos del sol.
}

14 En las Cartas literarias..., Bécquer menciona un viaje a Cádiz que debió de ser anterior a diciembre de 1860 . Ver Rica Brown, op. cit., p. 127.

Bécquer, Obras completas, Madrid, Aguilar, 1969, pág. 1114. 


Lleva en tus labios de grana
el hechizo seductor
de esa sonrisa que alegra
a mi amante corazón.
Lleva en el mágico acento
de tu perfumada voz
esa plácida armonía
del rico idioma español,
cuando al brotar de tus labios
nos muestra tu corazón.
Y si además de esto llevas
para mi insensato amor
un perfume de ternura
de tu ardiente corazón,
bendiga Dios ese baile
y bendiga el capuchón
que leyendo mis lamentos
mis súplica escuchó.

La historia no termina aquí. No sabemos el resultado de la cita, pero el 2 de febrero el gacetillero narra otro episodio que tiene también como personaje importante a la marquesita del Sauce, aun cuando ciertos elementos nos desorientan. El redactor nos informa de que ha recibido un billete pequeño y perfumado, escrito por mano de mujer, citándolo al baile que se celebraría en el Teatro Real. Se trata ahora de una máscara que oculta su identidad con un antifaz de terciopelo negro y un vestido y capuchón de color verde. El 3 de febrero se cuenta el encuentro en los corredores del teatro; el gacetillero, del brazo del dominó verde, entra en uno de los palcos reservados. El personaje aparece descrito con muchos detalles: los pliegues de raso de su disfraz ocultan a «una mujer de la alta sociedad». «Era un magnífico busto de mujer» (recuérdese la idéntica frase que aplica Blasco al desconocido amor de Bécquer); posee boca diminuta, cabellera sedosa, abundante y rizada (como la de la marquesa del Sauce) y otra vez una voz extraña, de inusitada suavidad, «pastosa y simpática, como exenta de esas vibraciones agudas que lastiman el oído y destruyen la ilusión». Parecería una nueva descripción de la misma belleza mejicana, si no fuera por el inesperado vuelco de la situación. El gacetillero habla con la enmascarada con palabras que recuerdan las de las Cartas literarias a una mujer:

Nosotros la hablamos, la hablamos de la vida práctica y de la vida del sentimiento; de la razón y del corazón; de la diferencia de hábitos que contribuye a la diversidad de círculos sociales, de la manera de sentir y de la manera de expresar, de lo.conveniente que es formar las frases para el efecto, ya previsto, que deben producir; de esas bellas y generosas naturalezas que habiendo nacido para brillar en el círculo de la inteligencia, vegetan y mueren en la región del lujo. 
Mientras la máscara verde y el periodista se engolfan en tal conversión, se abre de improviso la puerta del palco y aparece otro inesperado personaje: un caballero. La dama reacciona con gestos de sorpresa y de espanto. El relato se interrumpe hasta el 5 de febrero en que se lee la continuación. El caballero, un marqués, cambia palabras con el gacetillero, palabras que presagian un duelo. Esa consecuencia es evitada por otro personaje, un dominó de seda color de fuego, que entra también subitáneamente. La nueva máscara hace callar a ambos rivales «con un ademán de reina»:

-Señores, dijo, se trata de la reputación de una mujer: el que no la ame, que la comprometa.

-Pero -dijimos a un tiempo el marqués y nosotros.

- El que no la ame que la deshonre. Por lo demás, mi Pura (el dominó ver-

de) puede amar a usted porque es gacetillero; ni a usted (y se dirigió al marqués) porque no es capaz de ser gacetillero.

Y arrancándose la careta, el dominó de color de fuego dejó ver su semblante, «cuya belleza ni la ha materializado nunca el pincel, ni la ha soñado jamás el genio de la poesía». El marqués, anodadado, pronuncia su nombre: «iLa marquesa del Sauce!» Después de esto, cuando los demás personajes abandonan el palco, el dolorido gacetillero recoge el guante, olvidado sobre el diván, que había encubierto antes la mano de Pura; «aquel guante es el recuerdo que nos ha quedado de aquellas dos horas divinas».

La ficción, si es ficción, encubre una experiencia real: el gacetillero enamorado de la noble dama no tiene derecho alguno para su definitiva posesión por ser hombre de inferior categoría social. La historia sería perfecta si la dama de la Gacetilla fuese la marquesa del Sauce; pero la aparición de la marquesa como componedora de la situación quiebra la lógica del desenlace, tanto para nosotros como para los lectores contemporáneos. Existe sin embargo una contradicción que el periodista no se molesta en ocultar. El billete enviado por el dominó verde decía claramente:

Señor gacetillero: No conozco a usted ni a ninguno de su especie; y deseosa de saber positivamente lo que es un gacetillero, le ruego no falte esta noche al baile de máscaras del Real. A las dos, en el corredor de las plateas, frente al palco número... Un capuchón verde.

El desconocimiento a que se alude no es verdadero, ya que en el diálogo sostenido en el palco el dominó verde afirma con sincero énfasis: 
Me has amado durante un año y te he desdeñado durante ese año... Hoy que te he oido, que te he comprendido... quisiera ser libre para amarte. Mis padres dispondrán de mi suerte; pero yo, que dispongo de mis sentimientos...

Y la entrada del caballero la interrumpe. Creo que ese dominó verde es una creación del gacetillero, agregada al hecho real con el propósito de apartar la atención de los lectores de la verdadera protagonista. La misma marquesa del Sauce, o su familia, debieron de presionar sobre la dirección del periódico para terminar con esas indecorosas crónicas. La nueva ficción era el único modo de hacerlo, ya que exculpaciones más claras servirían sólo para aumentar el escándalo. Al inventar al personaje, el gacetillero le confiere como nombre el de Pura, que recuerda al de Casta, la joven soriana con la que Bécquer se casará meses después.

En el diario del 6 de febrero el gacetillero intenta asegurarnos de que se trata de un relato ficticio, sin explicar la presencia en él de un ser tan real como la marquesa. Con una ironía que encubre dolor, siguiendo el modelo de Larra (maestro de amantes despechados), critica, como Larra en Ya soy redactor, a los cajistas que cambian palabras y desvirtúan así la voluntad del escritor. Se refiere en concreto a las palabras de la marquesa del Sauce, que en verdad dijo ni Pura allí donde el copista leyó erróneamente mi Pura. Corrección insignificante, que apenas altera el sentido, pero que es buen pretexto para enfatizar que se trata de un relato ficticio, «de la aventura del dominó verde».

El 9 de febrero leemos en la Gacetilla «los siguientes versos escritos en papel fino y perfumado»:

\author{
Señor gacetillero; \\ esperar es virtud; \\ sufra y espere, \\ que también padece \\ la que de corazón le quiere.
}

El gacetillero responde con versos tan prosaicos como los de la dama, llenos de alusiones políticas contrarias a la Unión Liberal:

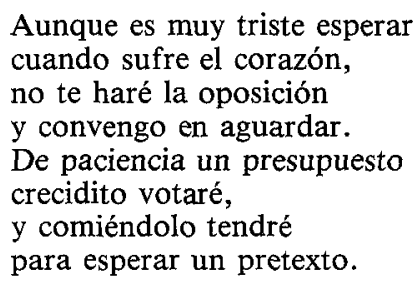



De este modo y con razón
veremos llegar un día
en que formar, vida mía,
la más entusiasta unión.
No digas a nadie nada
que el decirlo fuera un mal;
ya que espero liberal,
no me vengas resellada. ${ }^{16}$.

No hay más gacetillas de carácter tan personal en el resto del periódico. Las que hemos utilizado forman como una isla aparte en ese conglomerado de noticias y tienen un tono que no se repite. De tratarse, como creo, de una historia de amor algo escandalosa, no es extraña la permanencia de esa historia en el recuerdo de los contemporáneos de Bécquer y en la tradición de Soria.

Para aceptar esta historia amorosa como un hecho auténtico faltan pruebas más definitivas. En primer lugar, se necesita comprobar de modo irrefutable que el gacetillero es Bécquer y la marquesa del Sauce aquella enigmática dama de rumbo. Otros han supuesto ya que Bécquer es el responsable de las Gacetillas de El Contemporáneo. Según la autorizada opinión de Gamallo Fierros, Bécquer nutrió desde diciembre de 1860 «la sección Gacetilla de la Capital, y de un modo especialísimo, la de Variedades, que era el reducto literario del periódico» ${ }^{17}$. La Gacetilla del 22 de enero ha quedado incorporada sin mayor justificación a las Obras completas.

No hay duda alguna de que Bécquer pertenece por entonces a la redacción del periódico, ya que su nombre aparece en la nómina publicada el 23 de diciembre. El redactor de la Gacetilla es un andaluz, a juzgar por el uso hasta exagerado del loísmo y las constantes referencias a gentes y hechos de Andalucía. En la nómina aparece el nombre de otro andaluz, Felipe Carrasco de Molina, que según Gamallo es poeta de estilo muy similar al de Bécquer. Los dos pudieron ser responsables de esa sección del periódico, además, en forma conjunta, pues suele ser la Gacetilla resultado de la colaboración colectiva de los redactores más inexpertos, como ocurre aún hoy en las crónicas sociales. De ser Carrasco de Molina u otros los autores de esa historia, debería explicarse

16 Bécquer escribe versos de parecida intención política en varias oportunidades, refiriéndose sobre todo a la Unión Liberal, creada desde 1856 .Ver mi artículo «Los hermanos Bécquer en Gil Blas», Insula, 311, octubre de 1972, pág. 10.

17 Op. cit., pág. 37. 
un conjunto de coincidencias. Esos gacetilleros deberían ser amigos de Roberto Robert, de Antonio de Trueba, porque así se los califica en varios sueltos; deberían conocer precisos detalles con respecto al juicio contra los editores de la Historia de los Templos de España, cuyos resultados se comentan hacia esas fechas. Deberían además tener conocimiento de un poeta aún desconocido, amigo ya de Bécquer, Augusto Ferrán, cuya obra se anuncia el 10 de enero, días antes de aparecer el comentario crítico de Bécquer:

Pronto verá la luz pública una colección de cantares originales con los que, imitando los del pueblo, ha formado una preciosa colección el joven y modesto poeta D. Augusto Ferrán y Fornies.

Tan luego como el tomo obtenga la autorización fiscal competente, publicaremos nuestro juicio.

Sería aún coincidencia mayor que alguno de esos gacetilleros estuviese relacionado amorosamente con una dama aristocrática para las mismas fechas en que Bécquer pudo estarlo con la dama de rumbo. Tendría que darse también, por último, la circunstancia de que ese desconocido autor recogiera la idea de que las lágrimas de mujer producen perlas, como lo hace también Bécquer en Las perlas, y usara como Bécquer lo hace en La Caridad la frase «ángel de la Caridad», aplicada ahora a una mujer ${ }^{18}$.

Sólo indico indicios muy evidentes; pero podría aducirse también el tono becqueriano de la historia, sobre todo si se la compara con el espíritu algo larresco, por momentos burlón y hasta cínico, pero siempre poético en la descripción de paisajes y en la observación de la belleza', de las narraciones de Bécquer derivadas de crónicas sociales (El aderezo de esmeraldas, ¿Es raro!, Memorias de un pavo, El muerto al hoyo, La pereza, La ridiculez), y en general de aquellos escritos suyos en que describe con cierto pesimismo los usos de la vida moderna, en especial los de la clase alta.

La historia real que se desprende de las gacetillas tiene muchos puntos de contacto con lo que conocemos de esos amores de Bécquer. El poeta ha estado enamorado de una bellísima marquesa y esos amores fracasaron por las diferencias sociales y, según sabemos ahora, por la

18 «Las perlas» se publicó en El Contemporáneo, el 28, 29 y 30 de mayo de 1863; «La caridad» en EI Museo universal el 19 de noviembre de 1865; ver las frases aludidas en la cit. ed. de las Obras completas, págs. 667 y 1079. 
oposición paterna. La joven aristócrata cede su mano, en cambio, a un hombre de su misma clase. Esos amores tienen lugar desde antes de diciembre de 1860 hasta febrero de 1861. En marzo de ese año, Bécquer cae como consecuencia de un parecido fracaso amoroso en una profunda depresión expresada en su carta a Rodríguez Correa, si es que es - como creo- una carta auténtica:

Mañana emprendemos el camino de Veruela. ¡Ojalá el viejo monasterio me dé la calma y la resignación que necesito, pues mi alma es sólo un pobre guiñapo insensible, dormido, que me pesa como un fardo inútil que la fatalidad tiró sobre mis hombros, y con el cual me obliga a caminar como nuevo judío errante! En el amplio hogar de la cocina me entretuve anoche en quemar todas las cartas, únicos recuerdos - reliquias, mejor dicho-que me quedaban de mi vida de ayer, de las horas que nunca volverán. Al enroscarse a los rotos pliegues la llama parecía su mano, una mano amarilla, de muerte, que se burlaba de mí, haciendo signos incomprensibles, aquella mano que hoy estará prisionera entre otras. No quiero pensar nada, sentir nada ${ }^{19}$.

En El muerto al hoyo (9 de febrero de 1862), esbozo que Rica Brown considera con razón casi autobiográfico, Bécquer se refiere a un desengaño parecido. Su amada pasa junto a él en un lujosísimo carruaje: «Un hombre, que no quiero calificar, la acompañaba $\rangle^{20}$. Puede bien tratarse de la dama que según Blasco tenía otro «dueño». Una historia similar origina las Rimas más desgarradoras, las que suelen aparecer en las ediciones con los números XXX a LI.

Quizá alguien en España, con más posibilidades de comprobación que yo en los Estados Unidos, pueda rastrear en la historia de la nobleza española quién era en realidad esa mejicana marquesa del Sauce. Yo he esperado durante mucho tiempo hallar las pruebas definitivas pero ya no me resigno a mantener oculta entre mis papeles esta triste y todavía romántica historia de amor, cualquiera sea la realidad del hecho que encubre.

19 Carta dada a conocer por Iglesias Figueroa en La Voz, Madrid, 1 de enero de 1926. Recogida en Obras completas de Bécquer, págs. 1222-1223.

20 En Variedades de El Contemporáneo, Madrid, 9 de febrero de 1862. Transcribe parte del texto Rica Brown, op. cit., pág. 131. 